\title{
A ESPACIALIDADE DOS CONFLITOS SOCIAIS: AS JORNADAS DE JUNHO DE 2013 $^{1}$
}

\author{
The spatiality of social conflicts: the June 2013 Journeys
}

\author{
Glauco Bruce Rodrigues* \\ Tatiana Tramontani Ramos ** \\ *Professor do Programa de Pós-Graduação em Geografia - UFF - Campos dos Goytacazes - glauco_bruce@id.uff.br \\ ** Professor do Programa de Pós-Graduação em Geografia - UFF - Campos dos Goytacazes - tatiana_tramontani@id.uff.br \\ Recebido em 11/04/2019. Aceito para publicação em 20/04/2019. \\ Versão online publicada em 26/04/2019 (http://seer.ufrgs.br/paraonde)
}

\begin{abstract}
Resumo: Este trabalho busca apresentar, de forma introdutória e sintética, elementos teóricos e metodológicos que contribuam para os esforços já existentes de se apreender a espacialidade dos conflitos sociais a partir da Geografia. Buscamos apreender as relações entre espaço e ações sociais, particularmente no que se refere às práticas e estratégias espaciais dos protagonistas e em relação à centralidade do espaço geográfico como um elemento catalisador e motivador dos conflitos. Neste trabalho, delimitamos como objetos empíricos as Jornadas de Junho de 2013.
\end{abstract}

Palavras-chave: Espacialidade - conflitos - Jornadas de Junho

\begin{abstract}
This work seeks to present, introductory and synthetic form, theoretical and metodological elements that contribute to existing efforts to apprehend the spatiality of social conflicts from geography.We seek to capture the relationships between space and social actions, particularly in relation to spatial strategies and practices of the protagonists and to the centrality of geographical space as a catalyst and motivating element of conflict. In this particular research, to pinpoint how empirical objects June 2013 Journeys.
\end{abstract}

Key-words: Spatiality - social conflicts - June 2013 Journeys

\section{Colocando a questão}

As Jornadas de Junho de 2013 inauguraram uma nova conjuntura política, portanto, histórica, na sociedade brasileira. A conjuntura anterior compreende o período de 2003 a 2016, caracterizada pelo projeto de governo e de poder do Partido dos Trabalhadores, denominado por uns de Lulismo (SINGER, 2012) e outros de neodesenvolvimentismo (SAMPAIO JR, 2012; BOITO JR. 2012). De qualquer forma, tal período, grosso modo, é marcado por relativos, porém importantes avanços nas políticas públicas de distribuição de renda, aumento da capacidade de consumo das classes populares e, ao mesmo tempo, pela articulação com diversas frações de classe que permitiram elevadas taxas de lucro e de acumulação por parte do capital, principalmente nos setores agropecuário, financeiro e da construção civil. A nova conjuntura, inaugurada por Junho de 2013, é caracterizada pelo aumento da conflitividade, da polarização e da intensificação da luta de classes, cuja maior expressão é o avanço contra uma série de direitos dos trabalhadores através da aprovação do limite dos gastos públicos, reforma trabalhista e reforma da previdência (ainda não aprovada no momento), sem esquecermos do avanço de ideias e práticas conservadoras e reacionárias que caminham muito próximas ao fascismo e reforçam o racismo, a homofobia e o machismo estruturais.

O que a Geografia tem a dizer sobre isso? A questão mais geral que orienta essa pesquisa, no

\footnotetext{
${ }^{1}$ Esta pesquisa teve o apoio do CNPq
} 
âmbito disciplinar, é a análise da espacialidade da ação social, através da qual buscamos apreender e analisar as relações indissociáveis entre a ação social e o espaço geográfico. De forma mais específica, buscamos contribuir com o debate a partir da espacialidade de um tipo específico de ação social, que é o conflito. Partimos, portanto, de um lugar e de uma ação concretos e específicos, o que nos coloca desafios teóricos e metodológicos. Isso significa dizer que buscamos apreender as relações entre espaço e conflitos sociais, particularmente no que se refere às práticas e estratégias espaciais dos protagonistas e em relação à centralidade do espaço geográfico como um elemento catalisador e motivador dos conflitos.

Tentaremos demonstrar, através da análise, que os conflitos que instituem uma nova conjuntura política possuem uma clara e explícita dimensão espacial. Nesse sentido, a espacialidade foi um dos componentes centrais que nos permitem analisar e compreender os processos sociais atuais. Não queremos, com isso, sugerir algum tipo de hierarquia entre as diversas dimensões da vida social, mas apenas chamar a atenção para uma daquelas que é, geralmente, negligenciada no campo das ciências sociais.

A partir de junho, a dinâmica do espaço urbano ganhou centralidade nos debates políticos da sociedade brasileira, em todas as suas dimensões: o trabalho, a mobilidade, a habitação, a cultura, a segurança, o uso e a apropriação, o planejamento e a gestão. Tal conjuntura reforçou nossa convicção relativa à importância de se colocar no centro do debate a questão da espacialidade dos conflitos e ativismos sociais. Diversos conflitos, ações e manifestações tinham como causa a crítica à dinâmica urbana contemporânea, como, por exemplo, as lutas contra os aumentos das tarifas dos transportes públicos e as manifestações contra as remoções por conta das obras realizadas em função da Copa do Mundo e das Olimpíadas. Por conta disso, diversas lutas e debates se intensificaram ou ganharam maior notoriedade, apesar da sua existência anterior (como a luta por moradia e diretos humanos, particularmente no que se refere às lutas contra a violência policial em favelas e periferias).

Nesse contexto de aumento da conflitividade, na qual o espaço urbano desempenha um papel central, não podemos deixar de mencionar a ideia do direito à cidade, formulada por Henri Lefebvre, como uma das fontes de inspiração das ações, discursos e manifestações que ocorreram a partir de junho. Nessa perspectiva, as questões que nos interessam referem-se às lutas engendradas pela classe trabalhadora para se apropriar do espaço urbano, alterar as relações de poder que o constituem de forma desigual, democratizar o planejamento e a gestão, recolocar o sentido de viver, trabalhar e circular na cidade.

Assim, os conflitos que inauguram a nova conjuntura histórica brasileira tiveram na sua dimensão espacial um elemento crucial para compreender o desenvolvimento dos processos políticos que caracterizam o Brasil contemporâneo: as lutas contra o aumento da tarifa e contra os gastos e remoções para a realização dos megaeventos.

\section{Espaço e Conflitos Sociais}

0 conflito ${ }^{2}$ se torna uma chave analítica para a Geografia na medida em que parte da ação concreta dos sujeitos sociais e, mais especificamente, da contradição em estado prático, para a análise da espacialidade do social, ou seja, de processos mais amplos de produção do espaço e do território. Torna-se um ponto de partida e uma chave analítica privilegiada na medida em que possibilita a superação de dicotomias e esquemas hierárquicos de análise, desde que se incorpore a categoria de experiência como mediadora das estruturas e da ação social (THOMPSON, 1981).

\footnotetext{
2 Partir do conflito, em um sentido estrito, ou da luta social, em um sentido amplo, não é uma novidade em si para o conjunto das Ciências Humanas como um todo. Assim, a questão do conflito social não é nova. Na verdade, ela é central para as correntes do pensamento crítico que estão inseridas na tradição socialista, a saber, o marxismo, o anarquismo e o autonomismo. A despeito das diferenças, da heterogeneidade e dos conflitos existentes entre essas perspectivas e dentro de cada uma delas, acreditamos que é possível identificar como um elemento central da práxis de cada uma delas a ideia de conflito, que aparece de forma implícita ou explícita, dentro do conceito de luta de classes.
}

ParaOnde!?, Porto Alegre, v.11, n.1, p.90-104, 2019. http://seer.ufrgs.br/paraonde

Edição Especial: "Geografia e transformações socioespaciais: dinâmicas agrárias e políticas do desenvolvimento regional" 
A partir do conflito podemos puxar inúmeros fios que se entrelaçam formando tessituras complexas que nos permitem identificar elementos, processos e sujeitos que se relacionam, se articulam de diferentes formas, sem uma hierarquia dada a priori. A partir do conflito podemos puxar os fios das relações de produção, as diferentes formas de apropriação da natureza, as questões de gênero, o racismo estrutural, as diversas formas de representação e significação atribuída ao mundo material, aos processos de produção de subjetividade e identidade que costuram e dão consistência às relações sociais e de poder, podemos investigar e identificar as normas, as leis, os procedimentos, enfim, é possível tecer toda uma teia de relações sociais e de poder que remetem a escalas espaciais e períodos históricos distintos, que se articulam e cujo centro é a ação dos protagonistas.

Compreendido como um produto histórico e geográfico, o conflito não é indiferente ao tempo e ao lugar em que ocorre, ao contrário, tais coordenadas são fundamentais para compreendê-lo. É simples reconhecer a historicidade do conflito, no entanto, é fundamental ressaltar a sua espacialidade. Ele é produto, portador e devir de espacialidade.

Ele é o produto de uma determinada espacialidade que o conforma, mas, ao mesmo tempo, o conflito também é portador de uma determinada espacialidade que pode ser apreendida material e simbolicamente e que permite sua própria efetivação. Qualquer conflito se expressa materialmente, o que pressupõe uma espacialidade herdada mas, além disso, ele é, devir, possibilidade, força instituinte de uma nova espacialidade. Nessa peerspectiva, ele expressa, por fim, aquilo que Carlos Walter PortoGonçalves (2001 e 2003) denominou de "conflitos de territorialidade": se cada protagonista é portador de uma territorialidade própria que o constituiu e lhe dá sentido e o move de alguma forma, é possível pensar que o conflito explicita territorialidades distintas que se opõem. Daí todas as lutas que envolvem, direta ou indiretamente, o uso e a apropriação do espaço: lutas por reforma agrária, demarcação de territórios tradicionais, reforma urbana, direito à cidade, uso dos recursos naturais, entre outras.

O conflito é um evento. Sua duração pode ser determinada e seus limites são claros, pelo menos em relação à longa duração, ou à conjuntura. É a condensação de uma teia de relações que se expressa de forma concreta em um ato cuja duração pode variar de alguns minutos, até anos. Ele é produto histórico, pois é o resultado de ações que se iniciaram em outro momento e possuem temporalidades distintas, é o resultado singular de uma série de condicionamentos que não são redutíveis a ele. Portanto, é um produto histórico que deve ser apreendido nas múltiplas temporalidades (durações e ritmos) e historicidades (processos).

Ao mesmo tempo, o conflito também carrega em si a possibilidade de ser produtor de história, pois ele é potencialmente um ato criador, um marco que pode sinalizar rupturas e transformações, pode indicar o término de uma conjuntura e de uma longa duração e, ao mesmo tempo, do início de um novo período histórico. 0 conflito é potencialmente instituinte, uma vez que o processo é aberto e não circunscrito a nenhuma lei geral pré-determinada. 0 conflito, nesse sentido, pode indicar a superação de uma determinada contradição, o que implicaria, necessariamente, transformações estruturais na organização social. Por isso, ao mesmo tempo em que o conflito nos permite analisar o mundo tal como ele é, coloca a possibilidade de vislumbrar o mundo como ele poderia ser nas suas diversas possibilidades.

Podemos pensar o conflito em uma perspectiva radical, como o ponto de ruptura quando todas as formas de acomodação e reprodução das contradições falharam; o momento em que todos os limites são extrapolados e a ação é absolutamente necessária para se garantir a sobrevivência. No entanto, ele também se apresenta de formas mais mundanas e corriqueiras, quando as negociações falham, os acordos e formas de cooptação não são mais possíveis, as necessidades básicas do corpo têm que ser satisfeitas. Portanto, ao mesmo tempo em que o conflito comporta uma dimensão radical de ruptura societária, ele também expressa contradições e tensões do cotidiano que não apontam para rupturas, mas para a satisfação de necessidades básicas, ou conquistas de direitos e melhorias dentro da ordem estabelecida. Devemos deixar claro que não se trata, absolutamente, de hierarquizar o conteúdo de tais ações, não estamos propondo nenhum tipo de juízo de valor, mas apenas explicitando uma diferença de conteúdo.

Para0nde!?, Porto Alegre, v.11, n.1, p.90-104, 2019. http://seer.ufrgs.br/paraonde

Edição Especial: "Geografia e transformações socioespaciais: dinâmicas agrárias e políticas do desenvolvimento regional" 
A categoria conflito social nos abre, assim, novas perspectivas, pois possibilita a construção de um referencial teórico a partir do próprio lugar em que ele se dá. Embora possamos identificar padrões e até mesmo encontrar condicionantes históricos e geográficos, o conflito social como contradição em ato pode trazer novas questões a serem pensadas e teorizadas que se colocam a partir de lugares e situações que escapam aos padrões tanto teóricos, como políticos, estabelecidos. Assim, nossas investigações tanto apontam para a possibilidade de identificarmos padrões e processos gerais, como para as singularidades.

\section{Brevíssimas notas metodológicas}

A primeira questão que se coloca é: o que, efetivamente, deve-se entender por espacialidade dos conflitos sociais? É possível, em uma primeira aproximação, retomar as formulações do geógrafo Marcelo Lopes de Souza, que faz uma reflexão acerca da espacialidade dos ativismos sociais. Acreditamos que é absolutamente possível apreender os conflitos da mesma forma que os ativismos, conforme o autor propõe. 0 que ele nos diz? Ele afirma que as pesquisas acerca dos ativismos sociais devem ser capazes de revelar cinco dimensões dos ativismos e, que tais dimensões nos ajudariam a apreender sua espacialidade. Vejamos que dimensões são essas (SOUZA 2008, p. 368-369):

1. O espaço de referência identitária, ou seja, a identidade e a subjetividade coletiva produzida com uma referência explicitamente espacial que funda e constitui o próprio ativismo;

2. O espaço enquanto lugar, ou seja, os espaços vividos e percebidos, apropriados simbólica e afetivamente;

3. As estratégias espaciais, ou seja, as formas como o espaço é utilizado tática e estrategicamente pelos ativismos durante suas lutas;

4. A forma como o substrato espacial (a materialidade) influencia, condiciona ou determina as demandas ou questões que são a razão de existência do ativismo (concentração fundiária, carência e deficiência dos bens de consumo coletivo, poluição, desmatamento, segregação sócio-espacial, etc.);

5. As transformações espaciais realizadas pelos ativismos a partir das relações sociais e de poder produzidas de forma imanente. Novas relações sociais e de poder engendram novas espacialidades. Em outras palavras: que nova organização sócio-espacial é instituída pelo ativismo em questão.

Uma vez que o conflito é fruto da ação dos protagonistas, que nem sempre são ativismos sociais ${ }^{3}$, é possível buscar apreender as cinco dimensões que Souza propõe para o próprio conflito. Se substituirmos, na sua formulação, ativismos sociais por conflitos, o raciocínio permanece o mesmo. Vejamos: em determinado evento, é possível apreender um espaço de referência identitário explícito que é elemento constitutivo do próprio conflito? É possível articular ao conflito alguma dimensão do espaço enquanto lugar? De que forma o substrato material condiciona e influencia o início e o desenvolvimento do conflito? De que forma as estratégias e práticas espaciais dos protagonistas estão direta ou indiretamente influenciadas pela organização do espaço? Em suma, apreender a espacialidade do conflito significa identificar e explicitar as relações entre a ação e o espaço: até que ponto o espaço influencia e condiciona a emergência e a dinâmica do conflito.

0 trabalho de Ramos (2003) ${ }^{4}$ apresenta o que a autora chamou de atributos dos conflitos sociais. A análise dos atributos nos permite apreender as dimensões ressaltadas por Souza para uma análise

\footnotetext{
3 "os ativismos sociais (ou ativismos, simplesmente, para evitar uma redundância) são um conjunto mais amplo de ações públicas organizadas, do qual os movimentos sociais seriam um subconjunto. Os ativismos sociais, como ações públicas organizadas e relativamente duradouras, diferenciam-se de ações coletivas efêmeras e pouco organizadas ou desorganizadas, como quebra-quebras ("vandalismo de protesto"), saques e outras; e, como ações públicas, em sentido forte, diferenciam-se tanto da criminalidade ordinária (mesmo organizada) e de organizações terroristas, quanto de grupos de pressão e lobbies, em sentido restrito, que tendem a atuar nos "corredores do poder estatal", pressionando parlamentares ou administradores públicos e articulando tráfico de influência, entre outras atividades que não propriamente públicas" (SOUZA, 2006:278. Grifos no original).

${ }^{4}$ Este trabalho foi a sistematização de uma pesquisa coletiva desenvolvida no âmbito do Laboratório de Movimentos Sociais e Territorialidades, coordenada pelo professos Carlos Walter Porto Gonçalves e foi denominada Geografia dos Conflitos Sociais da América Latina e Caribe.
}

Para0nde!?, Porto Alegre, v.11, n.1, p.90-104, 2019. http://seer.ufrgs.br/paraonde Edição Especial: "Geografia e transformações socioespaciais: dinâmicas agrárias e políticas do desenvolvimento regional” 
explícita da espacialidade da ação social, no caso, dos conflitos. Os atributos são os seguintes:

1. Os protagonistas - Quem são aqueles que estão se colocando em movimento. O que pensam sobre si e sobre o mundo que vivem? Quais são as identidades produzidas (culturais, étnicas, políticas, espaciais, etc.), qual a sua base social, sua formação enquanto classe?

2. Os motivos e objetivos - Remetem às causas pelas quais as pessoas estão se mobilizando, seus objetivos e interesses. 0 que coloca as pessoas em movimento? Quais são as condições objetivas e subjetivas que mobilizam uma determinada coletividade? Quais são seus objetivos e projetos?

3. As formas de organização - Como determinado ativismo se organiza, como ele se estrutura para alcançar seus objetivos.

4. Os tipos de manifestações e estratégias de ação - São as práticas, ações e estratégias desenvolvidas pelos ativismos para conseguir alcançar seus objetivos. Quais são as estratégias espaciais utilizadas pelos protagonistas?

5. As escalas - Possuem um duplo aspecto, de extensão, quando informa sobre a área de abrangência e/ou ação de um ativismo, e de qualidade, que se refere à capacidade de articulação política e econômica e seu horizonte de luta política.

A análise de tais atributos, à luz dos balizamentos propostos por Souza (2008), nos permite produzir uma matriz metodológica cujo objetivo central é apreender a análise da espacialidade da ação social de forma indissociável de sua historicidade.

As Jornadas de Junho em si, em nossa perspectiva, são caracterizadas pela massificação das manifestações após o dia 13 de junho. Elas serão tratadas, metodologicamente, como um processo constituído por diversos conflitos que ocorreram entre junho e julho daquele ano. Portanto, compreendemos as Jornadas como uma microconjuntura (RIBEIRO, 2001) caracterizada por uma elevada conflitividade social e constituída por uma série de conflitos que ocorreram em inúmeras cidades brasileiras, com destaque para São Paulo, Rio de Janeiro, Porto Alegre, Salvador, Goiânia e Brasília.

Optamos por tratar as Jornadas como um processo e não como um único conflito que ocorreu em vários dias, em função da heterogeneidade de protagonistas envolvidos nas manifestações. Do ponto de vista metodológico, seria inconsistente tratar como um único conflito um processo caracterizado pela ação de protagonistas bem diferentes, sem uma organização em comum ou algum tipo de articulação, que tinham pautas e reivindicações distintas e com graus de radicalidade absolutamente diferentes.

Ainda no campo metodológico, apreendemos as Jornadas de Junho como um resultado de diversos processos que possuem escalas próprias e historicidades particulares (MAIA, 2016). Em outras palavras, as Jornadas de Junho não se explicam por si própria, tão pouco podem ser compreendidas como um fenômeno que se inicia e termina em junho. É necessário, portanto, identificar e articular elementos estruturais e conjunturais distintos que agem e influenciam processos e eventos em diferentes escalas e temporalidades.

\section{A dinâmica sócio-espacial de Junho}

Os eventos que deram origem às Jornadas não começaram em junho. Quis foram esses eventos? As manifestações pela redução das tarifas dos transportes públicos.

Na conjuntura de junho de 2013, os primeiros protestos contra o aumento das passagens ocorreram, em ordem cronológica, em Porto Alegre (dias 24, 25 e 27 de março, 8 de abril), Goiânia (8, 16, 21 e 28 de maio), Natal (15 e 24 de maio) e Salvador ( 2 de junho). Assim, o início dos protestos contra o aumento da tarifa tiveram uma origem fora do eixo Rio-SãoPaulo-Belo Horizonte, iniciando

Para0nde!?, Porto Alegre, v.11, n.1, p.90-104, 2019. http://seer.ufrgs.br/paraonde

Edição Especial: "Geografia e transformações socioespaciais: dinâmicas agrárias e políticas do desenvolvimento regional" 
em Porto Alegre, passando para Goiânia, Natal e Salvador antes de chegar em São Paulo.

Entre as primeiras manifestações pela redução da tarifa em Porto Alegre até a manifestação do dia 13 de junho em São Paulo, o que podemos observar é um conjunto de atos e manifestações organizadas por diversas organizações do movimento pela redução da tarifa, pelo passe livre ou engajados na questão da mobilidade, como o Movimento Passe Livre (organizado em diversos estados), a Frente de Luta do Transporte Público (Goiânia), o Bloco de Luta pelo Transporte Público (Porto Alegre), por exemplo. Esse primeiro conjunto de manifestações, composta fundamentalmente por estudantes secundaristas e universitários, organizados de forma relativamente autônoma e autogerida, independentes de partidos e sindicatos, tem uma pauta clara (a redução da tarifa), são constituídas por um sujeito coletivo que tem clareza de suas demandas (redução da tarifa, passe livre), compartilha um determinado projeto de cidade e de mundo (orientados, principalmente, pelo ideal libertário, seja anarquista ou autonomista) e contavam com um número relativamente reduzido de pessoas. Em suma, eram atos, que, apesar de sua vitalidade e disseminação em escala pelo território, eram caracterizado por certa coerência e consistência política de seus agentes. Entendemos que até esse momento não é possível falar em Jornadas de Junho. Analiticamente, reservamos o termo Jornadas de Junho para qualificar o processo de massificação e intensificação das manifestações que vai ocorrer somente após o dia 13 de junho, com a brutal repressão da PM paulista ao ato realizado na cidade de São Paulo, quando a marcha de aproximadamente 20 mil pessoas chega na Praça Roosevelt (JUNDENSNAIDER ET AL, 2013). É a partir daí que as manifestações ganham uma nova dimensão, tanto quantitativa quanto qualitativa. É em função dessa transformação que julgamos pertinente estabelecer esta distinção entre dois momentos dos conflitos de Junho de 2013: um primeiro período, caracterizado pelas lutas contra o aumento da tarifa, protagonizadas pelas organizações autônomas do movimento pelo passe livre, pela tarifa zero e pela mobilidade e outro momento de massificação das manifestações.

O fato de identificarmos o início das Jornadas em si para além do dia 13 de junho, não nos impede de afirmar, categoricamente, que elas só existiram em função da ação de todas as organizações engajadas na luta contra o aumento da tarifa. Assim, a gênese das Jornadas de Junho está na luta contra o aumento da tarifa. Sem a ação desses protagonistas, nenhum elemento da estrutura ou da conjuntura, por si só, seria capaz de engendrar um movimento de fora para dentro da sociedade. Sem a ação desses protagonistas, os elementos conjunturais que identificamos não teriam efetivamente com o que se articular, não teriam do que se alimentar para impulsionar a liberação de energia política que foi Junho de 2013. A repressão que ocorre no dia 13 de Junho em São Paulo repercute em todo o Brasil e, a partir desse episódio, as manifestações tomam a magnitude inesperada que pegou a todos de surpresa. A partir daí, as novas manifestações puxadas pelo MPL e outras organizações e coletivos passam, em um primeiro momento, a serem apoiadas por uma multidão a favor da luta contra o aumento. Em seguida, presenciamos o processo de difusão das pautas e, com a vitória alcançada em relação ao aumento, pois inúmeras cidades cancelaram o aumento da tarifa, o MPL se retira das manifestações e uma nova configuração política se instaura na dinâmica das manifestações, cujo embrião foi plantado já na massificação.

A questão que se coloca é: como e por que ocorreu tal massificação após o dia 13 de junho? Aqui, os elementos conjunturais são absolutamente necessários para compreender a adesão da população aos protestos. A insatisfação da população com o quadro político, as críticas aos gastos públicos com a Copa do Mundo e as Olimpíadas, a emergência do discurso conservador contra a corrupção e a violência policial do dia 13 de junho constituíram o contexto, ou melhor, a microconjuntura que massificou os protestos. Ou seja, houve a massificação das manifestações a partir desses elementos, no entanto, é necessário frisar que tal adesão se deu para os atos imediatamente convocados pelo MPL e outros coletivos, dependendo da cidade, cuja pauta era a redução da tarifa. A partir daí, as manifestações começam a ter um perfil heterogêneo em relação aos protagonistas e uma diversificação das pautas, apesar da centralidade da questão da tarifa ${ }^{5}$.

${ }^{5}$ Ressalva importante: como bem observam Tavares et al (2013), nem sempre as pautas foram fragmentadas e diversas como ocorreu

ParaOnde!?, Porto Alegre, v.11, n.1, p.90-104, 2019. http://seer.ufrgs.br/paraonde

Edição Especial: "Geografia e transformações socioespaciais: dinâmicas agrárias e políticas do desenvolvimento regional” 
Não há como analisar a massificação das manifestações sem analisar o papel fundamental desempenhado pela mídia hegemônica na produção do discurso sobre as manifestações e na disputa política e concreta do desenvolvimento das ações após o início das manifestações contra o aumento das tarifas. Durante o primeiro período, pré-Jornadas, a mídia hegemônica tratou as manifestações como caso de polícia: eram protestos sem sentido, que tumultuavam o cotidiano da cidade, faziam exigências impossíveis de serem cumpridas sem onerar os cofres públicos e, principalmente, eram violentas ou, no mínimo, descambavam para a violência. Em São Paulo, especificamente, os atos dos dias 6, 7 e 11, ocorrem ações violentas da polícia para reprimir as manifestações, utilizando o argumento de que era necessário garantir a paz e a ordem da cidade em função da violência promovida por grupos radicalizados. No dia 12, os jornais transmitidos pelas principais emissoras exigem uma dura resposta do governo para reprimir a manifestação do dia 13. Na manhã do dia 13, a Folha de São Paulo e o Estado de São Paulo publicam editoriais exigindo o máximo de rigor contra as manifestações. Por máximo rigor entende-se violência. A mídia hegemônica foi prontamente atendida e o massacre se deu na Praça Roosevelt.

Tamanha foi a barbárie policial que a própria mídia fez críticas ao comportamento da tropa no dia seguinte, principalmente em função da agressão sofrida por jornalistas que cobriam as manifestações. Daí em diante se observa uma mudança na forma de tratamento em relação aos protestos: até então, tratava-se de condenação e de se exigir a ação policial; agora, tratava-se de construir uma narrativa e, mais importante, influenciar no desenrolar dos acontecimentos. A partir daí podemos observar dois movimentos: 1. O discurso passa a legitimar as manifestações como um elemento crucial para a democracia, no entanto, construindo dois tipos de manifestantes, o pacífico e o vândalo; 2 . 0 discurso passa a focar em outras questões dispersas que aparecem em cartazes como se fossem as pautas que mobilizaram determinada manifestação e colocando em segundo plano a pauta central da tarifa, que foi aquela que aglutinou efetivamente as pessoas.

Nesse contexto, quem melhor consegue se apropriar e mobilizar essa energia não é a esquerda autônoma que puxou os atos contra o aumento das tarifas, tão pouco a esquerda governista. Em outras palavras, a esquerda autônoma mostrou claramente seus limites quando não conseguiu assumir a hegemonia do processo a partir da massificação dos protestos e a esquerda governista construiu a narrativa de que tais movimentos autônomos eram a ponta de lança das elites brasileiras e globais contra um governo popular (interpretação que julgamos equivocada). Quem consegue se apropriar de forma efetiva e afetiva de tal energia é a mídia hegemônica, que passa a canalizar e condicionar o desenvolvimento das ações a partir de interesses de classe bem claros: retirar a radicalidade da pauta da tarifa, domesticar e ampliar as pautas, de forma que as reivindicações tornem-se impossíveis de serem atendidas, pois não há foco ou clareza, desviar o conteúdo crítico das pautas para questão que, apesar de sua importância, são tratadas de forma moralista, como a luta contra a corrupção, que, naquele momento, era materializada na demanda pela aprovação da PEC 37; com isso, estava aberto o caminho para enfraquecer as administrações do Partido dos Trabalhadores em todos os níveis.

Quem eram esses novos e heterogêneos protagonistas? Uma pesquisa do Ibope, encomendada pela Rede Globo ${ }^{6}$ perguntou aos entrevistados qual a razão das manifestações, ou seja, o que levou a pessoa a se manifestar. A pesquisa apresenta dois resultados, o primeiro, quando era considerada apenas o primeiro motivo ou causa e o segundo, quando a pesquisa somou o resultado das três causas mais citadas pelos entrevistados. Em relação ao primeiro resultado, onde foi considerada apenas uma causa, a pesquisa mostra que a principal causa que levou as pessoas às manifestações foi o transporte público $(37,6 \%)$, no entanto, seguida de perto pela ambiente político $(29,9 \%$, o que inclui o combate à

na maioria dos atos em São Paulo e em grande parte do Rio de Janeiro. Em Goiânia, por exemplo, os atos não tiveram tal característica, sendo mantida a coesão das pautas. No Rio de Janeiro, por exemplo, onde Junho se estendeu até o início de 2014 , atos como o Ocupa Cabral, a Greve dos Professores, a Greve dos Garis, as assembleias populares no Largo de São Francisco também ajudam a relativizar tal generalização.

${ }_{6}^{6}$ http://g1.globo.com/brasil/noticia/2013/06/veja-integra-da-pesquisa-do-ibope-sobre-os-manifestantes.html. A pesquisa foi feita nas capitais de sete estados (SP, RJ, MG, RS, PE, CE, BA) e em Brasília na quinta-feira, dia 20. Foram entrevistados 2002 manifestantes com 14 anos ou mais, com margem de erro de 2 pontos percentuais para mais ou para menos. Segundo o Ibope, as entrevistas foram feitas por uma equipe de entrevistadores treinada para abordagem deste tipo de público.

ParaOnde!?, Porto Alegre, v.11, n.1, p.90-104, 2019. http://seer.ufrgs.br/paraonde

Edição Especial: "Geografia e transformações socioespaciais: dinâmicas agrárias e políticas do desenvolvimento regional” 
corrupção). Outras causas apontadas foram saúde (12,2\%), educação (5,3\%), gastos com Copa do Mundo e Olimpíadas (4,5\%). No entanto, quando a pesquisa apresenta o resultado das três principais causas para as manifestações, ambiente político aparece na frente com $65 \%$ e transporte público com $53,7 \%$. Já se percebe o resultado da fragmentação das pautas e da emergência da corrupção como grande mazela nacional a ser combatida, a despeito da grande importância dada a questão do transporte público.

A pesquisa mostra um perfil de manifestantes com predomínio de pessoas jovens $(63 \%$ entre 14 e 29 anos), com formação universitária (43\%) e com o ensino médio concluído ou iniciando a universidade (49\%). Em relação à renda familiar, 15\% ganha até 2 salários mínimos, 30\% ganha entre 2 e 5 salários mínimos, $26 \%$ ganha entre 5 e 10 salários e $23 \%$ ganha mais de 10 salários mínimos. $76 \%$ trabalham e $24 \%$ não trabalham.

O importante artigo de André Singer (2013) apresenta uma compilação de algumas pesquisas realizadas sobre o perfil dos manifestantes e mostra dados semelhantes: predomínio de jovens (88\% até 35 anos), elevada escolaridade ( $43 \%$ com curso superior completo, sendo que em São Paulo atingiu o patamar de $78 \%$ e Belo Horizonte 66\%), com exceção do Rio de Janeiro, onde a escolaridade registrada apresentava apenas $34 \%$ de grau superior completo. Em relação à renda familiar, os dados apresentados revelam que no Rio de Janeiro 88\% dos manifestantes ganhava até 5 salários mínimos (sendo que 34\% ganhava até 1 salário mínimo), enquanto em Belo Horizonte esse número era de 56\% (sendo que 20\% ganhava até 2 salários mínimos) e, para as demais capitais pesquisadas ${ }^{7}$ a média era de $45 \%$ até dois salários mínimos (sendo que 15\% recebia até 2 salários mínimos).

A importância do artigo está na análise que o autor retira desses dados. Em primeiro lugar, é refutada a ideia de que as manifestações eram amplamente protagonizadas pela classe média. Por outro lado, coloca elementos que apontam para a reduzida presença do que Souza (2008b) denominou de hiperprecariado. Se utilizarmos apenas os dados referentes à escolaridade, poderíamos imaginar uma população com uma renda mais elevada em função do grau de instrução, no entanto os dados sobre renda nos obrigam a relativizar e questionar essa afirmação. Não há dúvidas de que a classe média estava nas manifestações (com exceção do Rio de Janeiro, aproximadamente 23\% dos manifestantes declarou um rendimento maior do que 10 salários mínimos), no entanto, os dados de renda nos mostram a presença de uma população que tem maior acesso à educação, porém está inserida de forma subalterna e precarizada no mundo do trabalho. Somando-se o perfil predominantemente jovem, podemos sugerir a presença de uma geração que conseguiu maior acesso à educação através de uma série de programas de expansão e acesso ao ensino superior (REUNI, Prouni, FIES, expansão do ensino superior privado), marcas dos governos Lula e Dilma e de ampliação da escolaridade básica, que vinha ocorrendo desde o segundo mandato de Fernando Henrique Cardoso. Uma juventude que estuda e trabalha, inserida de forma precária no mercado de trabalho, com maior acesso à informação e formação. André Singer sugere a ideia do "cruzamento de classes", onde classes diferentes dividiram as ruas em Junho de 2013.

O cruzamento de classes, constituído por uma classe média e uma classe trabalhadora precarizada, porém com maior acesso a certos bens de consumo e com maior acesso à educação, é a característica dos protagonistas das Jornadas de Junho.

A partir dos dados que coletamos na imprensa ${ }^{8}$, é possível afirmar que o maior número de manifestações foi protagonizada por diversos grupos e frações de classe, dificultando uma identificação mais precisa, e, dessa forma, deixando clara a heterogeneidade das manifestações. Nesse sentido, as fontes falavam geralmente em "multidão", "manifestantes", sem nenhuma qualidade específica em relação à identidade dos protagonistas, o que poderia nos indicar também os motivos de suas lutas. Em um contexto de pautas fragmentadas, é plausível imaginar protagonistas heterogêneos e, em alguma medida, também fragmentados, pois compartilhavam, naquele momento, apenas a ideia de que ocupar a rua com seu corpo era uma forma de se fazer ouvir. Em segundo lugar, os estudantes

\footnotetext{
${ }^{7}$ São Paulo, Porto Alegre, Brasília, Salvador, Recife e Fortaleza.

${ }^{8}$ Analisamos aproximadamente 1000 notícias que relatavam manifestações e conflitos entre junho, julho e agosto de 2013.
} 
foram os grandes protagonistas dos conflitos referentes à luta contra o aumento da tarifa, além de participarem das demais manifestações relativas às críticas à Copa do Mundo e Olimpíadas. Entre maio e junho de 2013, quando o aumento das tarifas foi conquistado, os estudantes estavam à frente da mobilização e convocação dos atos, daí sua importância e destaque.

Apesar de tal heterogeneidade, a pesquisa revelou a centralidade da espacialidade para compreender esse processo. A dinâmica urbana é a espacialidade na e através da qual os conflitos podem emergir, na qual eles estão inscritos, na qual eles podem, de fato, se manifestar, ganhar existência e concretude. A questão urbana que os enquadra em certas condições de existência é constituída por elementos que influenciaram e condicionaram diretamente a existência de Junho: a mobilidade urbana, a segregação sócio-espacial, que no Brasil conjuga, ao mesmo tempo, a questão da classe e a questão racial; o debate sobre planejamento e gestão do espaço urbano a partir das prioridades e investimentos que devem ser realizados e as formas de se democratizar tais decisões; a oferta e os investimentos em serviços básicos (saúde, educação, cultura). Esses são os elementos centrais que podemos extrair da espacialidade como fundamentais para compreender Junho.

O espaço, nesse processo, é condição e suporte (material e subjetivo) da existência do conflito. Os protagonistas, através de suas ações, usam o espaço para engendrar processos de luta. Em nossa proposta teórica e metodológica, esse uso constitui um dos atributos do conflito, que denominamos tipos de manifestação.

A manifestação, em primeiro lugar, pode ser compreendida como uma tentativa de ocupar um espaço na arena política para se colocar como um sujeito ativo da construção do devir social. A partir do momento em que os protagonistas tornam-se públicos e se apresentam para o conflito, os desdobramentos de suas ações não se encerram no conflito em si, naquele ato. Cabe lembrar que não é necessário ocupar materialmente um espaço para se tornar público ou se apresentar para a luta. Isso pode ser feito através de manifestos, ações judiciais e afins. Queremos apenas salientar que a ocupação concreta do espaço é uma forma de se tornar público e se apresentar para o debate e para a luta. A busca pela visibilidade é uma constante nas lutas sociais. É evidente que a intensidade da visibilidade vai depender da força que esses protagonistas têm para ampliar suas escalas de ação. Protagonistas com maiores capacidades de articulação política e recursos econômicos, geralmente conseguem ampla visibilidade pública, o que não acontece com aqueles com menor capital político e econômico. Dessa forma, podemos dizer que a visibilidade pode variar entre um grau mínimo, que é aquela onde os protagonistas conseguem se fazer notar apenas pelos seus antagonistas diretos, até aquele que conseguem uma visibilidade global, como os Zapatistas, o MST, os movimentos anti-globalização entre outros.

Além da busca por visibilidade, é necessário conhecer os objetivos concretos e imediatos dos protagonistas, pois são eles que vão orientar a sua ação e, em larga medida, definir quais espaços serão apropriados. É possível que que exista uma correspondência entre o protagonista e seu repertório de manifestações, pois, dependendo de sua natureza, vão engendrar formas específicas de manifestações. No entanto, apenas as pesquisas concretas podem nos informar sobre isso. Basta observar, por exemplo, que em um único conflito podemos ter várias formas de manifestação (uma passeata que culmina na ocupação de um prédio público; atos de destruição de propriedade privada durante uma passeata; uma assembleia popular que decide, por algum motivo, sair em passeata; durante uma passeata os protagonistas bloqueiam ruas e avenidas) ${ }^{9}$.

Ao fazer o uso político do espaço, os protagonistas estão rompendo com uma determinada ordem, com uma determinada dinâmica sócio-espacial (o trânsito é afetado, atividades são paralisadas, a

\footnotetext{
${ }^{9}$ Não temos espaço, nesse momento, para um detalhamento maior sobre cada tipo de uso político do espaço através das manifestações dos protagonistas (para maiores detalhes, ver RAMOS, 2003). Para que o leitor possa ter uma ideia mais clara da dimensão espacial dessas ações, uma breve lista de formas de manifestação na qual o espaço é crucial para sua efetividade: atos, passetas e marchas no espaço público (ruas, evenidas, praças, rodovias), ocupações de terra, ocupações de prédios (públicos e privados) e piquetes. São apenas alguns exemplos cuja espacialidade é explícita.
}

ParaOnde!?, Porto Alegre, v.11, n.1, p.90-104, 2019. http://seer.ufrgs.br/paraonde

Edição Especial: "Geografia e transformações socioespaciais: dinâmicas agrárias e políticas do desenvolvimento regional" 
mobilidade fica reduzida, serviços deixam de ser oferecidos, etc.). Ora, romper com essa ordem os transforma, segundo a lógica e o discurso hegemônicos, em desordeiros, baderneiros, vândalos. Daí emerge o discurso de criminalização dos ativismos sociais, pois eles, de um lado, afetam a dinâmica imediata da ordem e, por outro lado, podem vir a colocar em questão a existência da própria ordem hegemônica.

Em Junho, o que chamou a atenção, foi a tomada maciça das ruas e praças pela população. A ocupação maciça do espaço público pela população foi uma das maiores da História contemporânea brasileira, levando em consideração as manifestações contra a ditadura, pelas Diretas Já e pelo impeachment do presidente Fernando Collor de Melo. A retomada momentânea das ruas pela população durante as Jornadas de Junho, se estendendo até o início de 2014, com as greves dos garis e dos professores no Rio de Janeiro, representaram, sem dúvida, uma demonstração de vida e potência da sociedade civil brasileira, que emergiu a partir da mobilização e ação de organizações de caráter libertário. A ocupação das ruas e avenidas foi capaz de derrotar o aumento das passagens naquele ano (em São Paulo e no Rio de Janeiro, o anúncio da manutenção do preço das passagens foi feito no dia 19 de junho). Ainda que pontual e efêmera, o movimento pelo passe livre, através de suas diversas organizações, conseguiu vencer os três maiores partidos do Brasil (PT, PSDB e PMDB) na batalha contra o aumento das passagens.

Em Junho identificamos quatro tipos mais frequentes de formas de manifestação: 1. os atos públicos em formas de passeatas; 2. o bloqueio de ruas e avenidas (via de regra conjugadas às passeatas); 3. o ataque à propriedade privada; 4. ocupação de prédios públicos.

As passeatas e atos públicos receberam tratamento diferente pela mídia hegemônica: até o dia 13 de junho os atos realizados contra o aumento da passagem eram tratados como caso de polícia, como bem relata o trabalho de Judensnaider et al (2013), no entanto, após o dia 13, as passeatas foram consideradas a forma legítima de manifestação e de exercício de democracia, desde que não houvesse nenhum tipo de ataque ao patrimônio público ou privado, desde que a passeata fosse considerada "ordeira" e obedecesse certas determinações do aparelho de Estado, o que significava, na prática, obediência ao aparelho repressor da polícia. Assim, quando as manifestações se tornaram maciças, as pautas foram fragmentadas e o aumento das tarifas foi derrubado, as passeatas foram consideradas a maior manifestação de exercício da democracia brasileira desde o impeachment do presidente Fernando Collor de melo, em 1992.

As passeatas eram convocadas, até o dia 19 de junho, pelas diversas organizações ligadas à questão da tarifa e por coletivos contrários à realização da Copa do Mundo (devemos lembrar que em junho de 2013 estava sendo realizada a Copa das Confederações no Brasil, evento preparatório para a Copa do Mundo, no ano seguinte). A dinâmica era semelhante: ocorria a concentração em um ou mais pontos da cidade e, após a concentração, a passeata iniciava sua apropriação das ruas e avenidas da cidade. Durante o percurso, várias músicas, bandeiras, faixas e palavras de ordem. 0 corpo da multidão, que até o dia 13 e nas manifestações imediatamente seguintes, era relativamente coeso em relação às reivindicações (impedir o aumento da tarifa), tomava o espaço da cidade, impedia a circulação de sues fluxos, alterava sua dinâmica cotidiana. Aliás, o noticiário, até o dia 13 de junho, estava muito mais preocupado com o impacto causado no trânsito do que com a pauta das manifestações.

Um dos aspectos mais importantes, evidentemente, é de se pensar estrategicamente o uso do espaço. No documentário "A partir de Agora", de Carlos Pronzato, uma das militantes do MPL-SP, afirma que o movimento mudou de estratégia em 2013: a ideia agora era de convocar a maior quantidade possível de atos no menor espaço de tempo possível e de forma descentralizada, buscando atingir diversas áreas da cidade ao mesmo tempo. No mesmo documentário, outro militante afirma que a ideia era de que os protestos saíssem de controle, o que, de fato, aconteceu. Assim, questões relativas ao horário, dia, frequência e localização das ações são fundamentais. Em que horário do dia é mais vantajoso se fazer uma manifestação? É comum que manifestações nos horários de rush sejam mal vistas e não tenham a solidariedade dos demais trabalhadores, por outro lado, é importante ter visibilidade; da mesma forma, coloca-se a questão de onde se fazer uma ação, pois é necessário que ela

Para0nde!?, Porto Alegre, v.11, n.1, p.90-104, 2019. http://seer.ufrgs.br/paraonde

Edição Especial: "Geografia e transformações socioespaciais: dinâmicas agrárias e políticas do desenvolvimento regional" 
surta algum efeito, que gere ou produza algum dano. Nas Jornadas, as passeatas ocorreram nos mais diversos dias e horários, seguindo mais a lógica do maior número possível de atos, puxados geralmente no final da tarde e que adentravam a noite, sendo que nos fins de semana as passeatas eram marcadas, geralmente, na parte da manhã e se estendiam até a tarde.

O bloqueio de ruas estava conjugado a duas outras formas de manifestação: em primeiro lugar, evidentemente, às passeatas, que fechavam parcial ou completamente as ruas e avenidas pelas quais passava e, em segundo lugar, associadas a episódios de ataques da polícia aos black blocs, que começavam, na maioria das vezes, sem nenhum tipo de provocação por parte dos manifestantes ou quando havia a ocorrência de algum tipo de ataque ao patrimônio público ou privado. Nesse segundo caso, era comum o bloqueio das ruas em função do conflito em si ou em função da criação de frágeis e precárias barricadas criadas com pneus, lixeiras e qualquer tipo de material disponível para se criar um obstáculo ao avanço das forças policiais.

0 ataque à propriedade, seja pública ou privada, se dava basicamente em duas situações: 1. após ataques da força policial contra os manifestantes, o que causava indignação e revolta nos manifestantes, desencadeando episódios de violência; 2. os ataques conscientes e planejados dos black blocs aos símbolos do capitalismo, principalmente bancos, mas atingindo também outros estabelecimentos comerciais, como lojas de carros importados, lanchonetes e outros.

Por fim, um tipo de manifestação interessante foi a ocupação de prédios públicos, principalmente prefeituras e assembleias legislativas. Aqui podemos observar três ações distintas: 1. a ocupação não do prédio em si, mas das suas áreas externas (redondezas, telhados, escadarias); 2. ocupação momentânea do prédio, que podia durar de alguns minutos a algumas horas; 3. ocupação contínua do prédio $^{10}$, na qual os manifestantes se recusavam a deixar o local e constituíam coletivos, geralmente inspirados em princípios libertários, que construíam pautas de reivindicação e formas de organização interna da ocupação através da autogestão (instituindo assembleias deliberativas e sistemas de delegação). No contexto de Junho, a ocupação desses espaços significava basicamente duas coisas: 1. a revolta e a insatisfação generalizada da população com a dinâmica da política brasileira e com o início da crise econômica; 2 . estratégia para demandar a redução do preço da tarifa.

De qualquer forma, a despeito das diferenças entre cada uma delas, o elemento que há em comum é o fato de prédios públicos, geralmente caracterizados pela distância entre a população e o aparelho de Estado, geralmente tão hostis e burocratizados à presença da sociedade civil ou, de forma mais simples, à presença do cidadão, serem reapropriados pela população. Em outras palavras, espaços tão rígidos, distantes e impermeáveis à participação popular, distantes do cotidiano das pessoas, são reapropriados, ainda que temporariamente, como forma de demonstrar a insatisfação com a dinâmica da burocracia política e estatal, incapaz de dar respostas eficientes e concretas aos problemas e anseios da população, insatisfação com o abismo entre a representação e a efetiva participação política, na condução e decisão dos assuntos públicos. Assim, quando a população ocupa um prédio público, ela está demonstrando sua insatisfação e assumindo um protagonismo político através da ação direta, com o objetivo de exigir e demandar do aparelho de Estado respostas para seus problemas (que podem ou não ser imediatos). No caso das Jornadas de Junho, as ocupações ocorrem principalmente em prefeituras, assembleias e câmaras legislativas e no Congresso Nacional. Esses lugares não foram escolhidos de forma aleatória, mas por representarem, no imaginário social, os lugares onde as decisões são tomadas e as leis são criadas. O sentido mais profundo da ocupação desses espaços é a busca por uma participação política mais efetiva, uma redução na distância entre o cidadão comum e o processo de elaboração de leis e tomada de decisões. 0 ataque a esses prédios significa um ataque à dinâmica política da sociedade, um ataque, ainda que efêmero, à forma como o modo de existência está organizado para perpetuar todo tipo de hierarquização, dominação e separação entre as classes. Talvez o exemplo mais radical desse processo tenha sido a batalha da Alerj,

\footnotetext{
10 Talvez a experiência mais duradoura, em Junho de 2013, tenha sido da ocupação da Câmara Municipal de Belo Horizonte pela Assembleia Popular Horizontal, no dia 29/6/13 e durou nove dias, quando se encerrou em função da iminente invasão da Tropa de Choque que já se preparava para a ação. Ver Ferreira (2016)

http://www.eng2016.agb.org.br/resources/anais/7/1468244019_ARQUIVO_XVIIIENGtulioc.pdf
}

ParaOnde!?, Porto Alegre, v.11, n.1, p.90-104, 2019. http://seer.ufrgs.br/paraonde

Edição Especial: "Geografia e transformações socioespaciais: dinâmicas agrárias e políticas do desenvolvimento regional” 
no Rio de Janeiro, no dia 17 de Junho, onde a ação dos manifestantes deixava clara a insatisfação, a raiva e a indignação. 0 enfrentamento com as forças policiais foi intenso e as imagens, disponíveis em inúmeros vídeos na internet, não deixam dúvida da radicalidade do conflito.

Evidentemente que tal ataque à reprodução das desigualdades não passava impune: contra aqueles que se manifestavam, o Estado lançava mão de todo seu aparato repressor, utilizando a tropa de choque, a cavalaria, cassetete, balas de borracha, bombas de efeito moral e de gás lacrimogêneo, spray de pimenta e teasers. Uma observação importante: não foram apenas os governos de centrodireita que utilizaram amplamente a violência para reprimir as manifestações; o Partido dos Trabalhadores e seus aliados criticaram, criminalirazam e reprimiram de forma tão dura quanto seus adversários políticos institucionais. Houve uma união entre PT, PSDB, PMDB e seus aliados na repressão aos movimentos que lutaram pela revogação do aumento das tarifas.

As táticas da repressão também mudavam de acordo com o desenvolvimento das ações: nos primeiros atos a PM atacava a manifestação já em curso; depois, passou a impedir que a manifestação começasse, fazendo um cinturão ao redor da concentração e impedindo as pessoas de sair ou entrar; a retirada dos nomes dos policiais da farda para impedir a identificação e o uso da "tropa do braço" (policiais treinados em artes marciais) para conter os manifestantes sem o uso de armas. É possível afirmar que na maioria das manifestações a polícia militar atacou primeiro ou utilizou a ação do black bloc como justificativa para iniciar a repressão, sempre afirmando estar defendendo o direito à manifestação, garantindo a segurança dos manifestantes e protegendo o patrimônio da ações de "vândalos".

\section{Uma síntese}

As Jornadas de Junho representam o fim do projeto do Partido dos Trabalhadores ou, para certos autores já citados, a crise do lulismo, baseado na conciliação de classes através do controle da luta de classes, expansão do crédito para consumo, subsídios para determinados setores do capital (agronegócio e construção civil), expansão das universidades e do crédito estudantil, por exemplo. A crise deste projeto é indissociável de uma crise mais ampla da frágil democracia brasileira, caracterizada pela forte desigualdade socioeconômica, pelo racismo estrutural, elevada concentração de renda, pela desilusão e repulsa da população em relação à dinâmica política do país. Representou, dentro de um quadro mais amplo, um momento de crise da democracia representativa.

A crise do projeto do Partido dos Trabalhadores inaugurou uma nova conjuntura na sociedade brasileira, marcada pela ascensão de forças conservadoras e reacionárias, de diversos campos do espectro político de direita, desde de neofascistas e ultraliberais, que passaram a exercer a hegemonia política no Brasil, o que se consolidou com o impeachment da presidenta Dilma Rousseff e o início das reformas trabalhista (aprovada), os limites para os gatos públicos (aprovado) e previdenciária (ainda não aprovada), além de uma série de medidas que favorecem abertamente as diferentes frações de classe capitalista em detrimento dos direitos dos trabalhadores. A conjuntura que se iniciou em 2013 tomou corpo em 2014 e 2015 e se consolidou efetivamente nos anos de 2016 e 2017, caracterizada pelo aumento da conflitividade social e polarização cada vez maior da sociedade brasileira. 0 ápice foi a eleição de Jair Bolsonaro para a presidência da República em 2018. A instauração de tal conjuntura não foi resultado da ação das organizações que mobilizaram a população contra o aumento das tarifas, mas sim o resultado das relações de poder que se colocaram naquele momento, na tentativa de catalisar a ação social e sua potencialidade. Nesse processo, os setores conservadores e reacionários tiveram sucesso.

A ascensão do conservadorismo, de campos reacionários e ultraliberais demonstrou claramente os limites da esquerda libertária que conseguiu mobilizar a sociedade brasileira e engendrar um dos maiores processos de conflito social e de manifestações nos últimos 25 anos. Se, por um lado, o campo libertário, constituído, principalmente, por autonomistas e anarquistas, foi capaz de construir uma 
mobilização desse tipo, contando com condições específicas da conjuntura, por outro, ele mostrou seus limites para orientar o processo visando uma radicalização maior da experiência.

Por outro lado, a esquerda institucional, que elege a via eleitoral e a apropriação do aparelho de Estado como a principal (às vezes única) estratégia de luta, condenou as manifestações, de forma geral, concebendo-as como uma forma de enfraquecimento do projeto do Partido dos Trabalhadores. Nessa perspectiva, não conseguiram compreender o significado daquele processo e pouco fizeram para reverter o quadro através de ações concretas que fossem ao encontro dos anseios das ruas.

Finalmente, depois de seis anos dos conflitos, é possível afirmar que Junho deixou alguns frutos, porém não duradouros. Quais foram os frutos ou conquistas de Junho? Em primeiro lugar, as manifestações conseguiram barrar o aumento das tarifas em inúmeras cidades brasileiras. Um exemplo empírico que a luta é capaz de trazer transformações concretas e imediatas para a vida. Portanto, lutar não é em vão. Em segundo lugar, houve um ganho, talvez mais duradouro, no campo pedagógico. Junho serviu como uma experiência de aprendizado político para uma nova geração que nunca tinha participado de algum tipo de luta, militância ou, simplesmente, de uma manifestação. As pessoas passaram a debater e a se posicionar mais perante as questões. É certo que a qualidade dos debates é baixa, devido à má formação intelectual e cultural estrutural, reforçada por todo tipo de miopia e torpeza ideológica, que transforma debates em lutas, gritos e violência. No entanto, é possível perceber que houve uma aprendizagem política nessa experiência. Tal aprendizagem repercutiu nas ocupações de escolas e universidades ao longo de 2015 e 2016. É possível verificar nessas experiências as influências e referências aos princípios libertários que moveram as mobilizações contra o aumento das tarifas. A perspectiva horizontal, as assembleias, a delegação de poder, a rejeição à organizações burocráticas e hierarquizadas, todos esses traços, estavam presentes nas organizações e coletivos que puxaram as mobilizações contra o aumento das tarifas.

No entanto, tais frutos são pequenos, frágeis e, infelizmente, não se mostraram à altura do desafio histórico de se contrapor, de forma efetiva e ativa contra um conjunto de forças políticas francamente conservadoras, reacionárias, que explicitaram um projeto autoritário de sociedade, cujo ápice foi a vitória eleitoral do atual presidente da República. Durante certo tempo, Junho foi tido como um mito, um processo emancipatório, como algo que iria, finalmente, despertar a sociedade brasileira rumo a algo melhor. Não foi. Junho não foi um processo pré-revolucionário, não foram jornadas inssurrecionais, não apontaram e não levaram à maior organização e mobilização da classe trabalhadora. As ilusões em relação à Junho devem ser abandonadas se quiseremos, efetivamente, construir uma sociedade minimamente democrática.

\section{Referências}

ARBEX JR., José. É a conjuntura, estúpido! Disponível em encurtador.com.br/ozIZ4

BOITO JR, Armando. As bases políticas do neodesenvolvimentismo. Fórum Econômico da FGV-SP. 2012. Disponível em encurtador.com.br/lmyAG.

BORBA, Maria; FELIZI, Natasha e REYS, João Paulo. (orgs.) Brasil em movimento: reflexões a partir dos protestos de junho. Rio de Janeiro: Rocco, 2014.

BRAGA, Rui. A política do precariado: do populismo à hegemonia lulista. São Paulo: Boitempo. 2012

BRANCALEONE, Cassio e DE BEM, Daniel. (orgs.) As rebeliões da tarifa e as jornadas de junho no Brasil. Porto Alegre: Editora Deriva, 2014.

FERNANDES, Bernardo Mançano. MST: formação e territorialização. São Paulo. Hucitec. 1996.

. A formação do MST no Brasil. Petrópolis: Editora Vozes. 2000a.

ParaOnde!?, Porto Alegre, v.11, n.1, p.90-104, 2019. http://seer.ufrgs.br/paraonde

Edição Especial: “Geografia e transformações socioespaciais: dinâmicas agrárias e políticas do desenvolvimento regional” 
Movimento social como categoria geográfica. Terra Livre. São Paulo: AGB. Pg. 59-86. 2000b.

FERREIRA, Túli César T. A assembleia popular horizontal e a luta pela cidade. In. Anais do XVIII Encontro Nacional de Geógrafos. São Luiz. 2018.

GONÇALVES, Carlos Walter Porto. A territorialidade seringueira. Geographia. Ano 1, nํ2, pgs. 67-96. Dezembro. 1999.

Geo-Grafias- Movimentos sociales, nuevas territorialidades y sustentabilidad. Guadalajara: Siglo Veintiuno editores. 2001.

Geografando: nos varadouros do mundo: da territorialidade seringalista à territorialidade seringueira ou do seringal à reserva extrativista. Brasília.IBAMA/MMA. 2003.

HARVEY, David. A justiça social e a cidade. São Paulo. Hucitec. 1980.

Condição Pós-Moderna. São Paulo. Loyola. 1996.

JUDENSNAIDER, Elena. Et al. Vinte centavos: a luta contra o aumento. São Paulo: Veneta, 2013.

LEFEBVRE, Henri. 0 direito à cidade. São Paulo. Editora Documentos. 1969.

MAIA, Lucas. Nem partidos, nem sindicatos- a reemergência das lutas autônomas no Brasil. Goiânia: Edições Redelp. 2016.

MARICATO, Ermínia. É a questão urbana, estúpido! In. Maricato, Ermínia et. al. Cidades Rebeldes: Passe Livre e as manifestações que tomaram as ruas do Brasil. São Paulo. Boitempo e Carta Maior. 2013.

RAMOS, Tatiana Tramontani. A Geografia dos Conflitos Sociais da América Latina e Caribe. Programa Regional de Becas Clacso. 2003.20 Disponível http://bibliotecavirtual.clacso.org.ar/ar/libros/becas/2002/mov/tramon.pdf

RIBEIRO, Ana Clara Torres. Micro-conjuntura: uma proposta de análise da aceleração da vida urbana. Revista de Ciências Sociais, no 19, pgs. 94-103. 2001

Leituras de Movimentos: conjuntura, ação e poder. In. RIBEIRO, Ana Clara Torres. Por uma sociologia do presente: ação, técnica e espaço. Rio de Janeiro: Letra Capital. 2013.

SADER, Eder. Quando novos personagens entram em cena: Experiências e lutas dos trabalhadores da Grande São Paulo, 1970-1980. Rio de Janeiro: Paz e Terra. 1988.

SAMPAIO Jr. Plínio. Desenvolvimentismo e neodesenvolvimentismo: tragédia e farsa. Serviço Social e Sociedade, no 112, pp. 672-688, São Paulo. 2012.

SANTOS, Milton. A natureza do espaço. Hucitec. São Paulo. 1996.

Por uma Geografia Nova. Rio de Janeiro. Record. 2002 [1978].

SINGER, André, Os sentidos do lulismo: reforma gradual e pacto conservador. São Paulo. Companhia das Letras. 2012. nov. 2013

Brasil, junho de 2013: classes e ideologias cruzadas. Novos estudos. CEBRAP, n. 97, São Paulo, SOUZA, Marcelo Lopes de. 0 desafio metropolitano. Rio de Janeiro: Bertrand Brasil. 2000.

Mudar a cidade: Uma introdução crítica ao planejamento e à gestão urbanos. Rio de Janeiro: Bertrand Brasil, 2003.

. A prisão e a ágora. Rio de Janeiro. Bertrand Brasil. 2006.

"Ativismos sociais e espaço urbano: Um panorama conciso da produção intelectual brasileira". In. OLIVEIRA, M. Piñon; COELHO, Maria Célia N. e CORRÊA Aureanice M. o Brasil, a América Latina e o mundo: Espacialidades contemporâneas II. Rio de Janeiro: Lamparina, FAPERJ, ANPEGE, 2008. 
Fobópole: o medo generalizado e a militarização da questão urbana. Rio de Janeiro: Bertrand Brasil, 2008b.

TAVARES, Francisco Mata Machado et al. As jornadas de maio em Goiânia: para além de uma visão sudestecêntrica do junho brasileiro em 2013. Opinião Pública. Campinas, Vol. 1, no 22, abril. 2016. THOMPSON, E. A miséria da teoria. Zahar. Rio de Janeiro. 1981.

Costumes em comum. São Paulo. Cia das Letras. 1998.

VINÍCIUS, Léo. Guerra da Tarifa 2005: uma visão de dentro do movimento passe-livre em Floripa. São Paulo: Faísca Publicações Libertárias, 2006. 